\title{
The Research on the Assessment of the College Aerobics Teaching Quality Based on Grey-TOPSIS-DEA Method and the Computer Simulation
}

\author{
Meng Sun \\ Xi'an Technological University, No.2 Xuefuzhonglu Weiyang College Park, Xi'an, \\ Shaanxi, China \\ 595187014@qq.com

\begin{abstract}
Since the major colleges and universities introduce the Aerobics, the a robics is highly popular in teachers and students. However, it is lack of the effective tearhing quality evaluation method while many colleges study the aexobics. Aerobics teaching quality evaluation can not only strengthen the college aergbics management byt also promote the further development of the college aerobics. TOPSIS method is one of the traditional evaluation methods. However, it cannot reflect the changers among the projects and the differences between the positive solutions and the negativecsolutions. In this paper, we put forward a Grey-TOPSIS-DEA method. And we use the method to evaluate college aerobics teaching. The experimental results show that the method can better achieve the
\end{abstract} \\ study purpose.
}

Keywords: college aerobics, tedching quatity, TOPSIS, DEA

\section{Introduction}

In the last century 80's, the Aerobics was introduced into China and developed vigorously. In order to meet the demand of teachers and students in the major colleges and improving the students' physical qualities, many colleges carried out the relative courses of the aerobics. The aerobies was one aerobic exercise which combined the music, dance with the sports. In 1983, America held the first aerobics competition. From 1992, our country started the annual national tournament aerobics.

Zhang Xiaoying and other people researched on Cultivating Students' Creativity Ability in the Teaching of Special Curriculum of Aerobics [1]. The author analyzed the current situation of gerobics innovation education. On this basis, combined the successful experience of the college reform with the features of the aerobics, the author reformed the origina model of the aerobics calisthenics teaching. He strengthened the professional foundation and paid attention to the social practice. Li Yunlin and Chen Min researched on artistic value of new code aerobics composition [2]. According to the experting interviews and watching the video game, the author interpreted the current status of China's competitive aerobics set design. And he put forward the new concept of the set movement arrangement. This provided a theoretical reference for the choreography of China's competitive aerobics and promoted further the competitive aerobics level. Yao Liqin studied evolution characteristics for the international competitive calisthenics rule [2]. According to comparing and analyzing comprehensively the international competitive calisthenics rule, the author got the following conclusion. The art scoring factors were more and more reasonable. The project characteristics were elevated to an unprecedented height. The total numbers of the high level of difficulty actions were more. At the same time, the requirements for completing the action were much higher [3]. Li Ling researched the aerobics dynamic analysis in China during 1992-2011 [4]. She thought that 
the total quantity of our aerobics research direction was bigger. However, the distribution was not uneven and the depth was not same. The research object was too single. In addition, the research which compared with other fields was less and it was lack of the research deep. Yang Xiao researched of the aerobics professional teaching ability of the graduations of Henan University [5]. The author thought that the companies satisfied of the aerobics teaching ability for the graduates of Henan universities. However, the self-assessment for the graduates illustrated that the aerobics teaching ability is in the middle level. The graduates thought that their aerobics teaching ability needed to be improved. Yang Guang researched the group cooperative learning method in college aerobics teaching [6]. The author constructed the group cooperative learning method and the method was applied to the aerobics teaching in colleges. In addition, the author did the teaching compared experiment in aerobics elective course. The research results/showed that group cooperative learning method had the positive impact on the innovation ability, self-learning, teaching ability, social adaptation ability and training ability for the college students.

The full name of TOPSIS method is the technique for order preference by similarity to ideal solution and is also known as the ideal point method It was proposed by C. L. Hwang and K. Yoon in 1981. The advantage of ATOPSIS is that the application is convenient, reasonable and easy to understand. The alernatixes solution can be described by the simple mathematical form. And the method can also use the objective weight in the process of comparison. Based on the above advantages 4 TOPSIS method has applied successfully in many fields. And it enhanced significantly the scientific and the operation for the multi objective decision [t-11]. Ksenija Mandic etc. proposed a fuzzy multi-criteria model. This model could promota the assessment of the banks financial performance. The author analyzed the financial performance of the banking sector in Serbia between the 2005 and 2010. The proposed model integrated the method such as the Fuzzy Analytic Hierarchy Brocess (FAHP) and the Technique for Order Performance by Similarity to Ideal Solution (TOPSIS) 121. Ting-Yu Chen developed an extended TOPSIS method with an inclusive comparison approach for addressing multiple criteria group decision-making problems in the framework of interval-valued intuitionistic fuzzy sets. The aim of the study for author was to propose a modified hybrid method with an inclusion-based ordered eighted averaging operation to take shape of a collective decision environment with considering the relative agreement degrees and the importance weights of multiple decision makers [13]. In 1987, A. Charnes, W. Cooper and E. Rhode got the data enyelopment analysis method. As a rigorous scientific evaluation and optimization theory, the DEA method has applied successfully in many fields according to the development of decades [14-18]. From the two aspects of the input and output, Ma Lijie put for vard a new input-output type double criteria DEA model [19]. Aiming at the insufficient information of the decision unit that the data envelopment analysis reflected, Wang Quanhua established the data envelopment model which brought the parameters. The models were PC2R model and PBC2 model. The model got the new indexes of the evaluation decision unit. Secondly, due to the insufficient information or measurement error, the input-output data of the decision unit may be the intervals. This established the interval data envelopment analysis model which was based on the maximum production possibility set. They were IC2R model and IBC2 model. Finally, according to the extended data envelopment analysis thought and method, we established the extended interval data envelopment analysis model which was based on the maximum production possibility set. They were EIC2R model and EIBC2 model. And it gave the indexes of the evaluation decision unit [20]. From the view of the environmental efficiency, Bian Yiwen applied the data envelopment theory to study the theory and method for the evaluation of the environmental efficiency. Based on the evaluation model of environmental efficiency, he put forward a kind of method to analyze the environmental efficiency from the view of the input-output simultaneously. Based on the additive DEA model, we considered the 
relaxed value for the input-output of the decision unit. Then we used the example analysis to illustrate the model that was proposed in this paper and the rationality of the method [21].

In this paper, in order to evaluate the college aerobics teaching quality, we combined the TOPSIS method with the DEA method. And we proposed the Grey-TOPSIS-DEA method. This method combined Grey model, TOPSOS with DEA and overcomes the shortcomings of the traditional methods. We established the evaluation system of aerobics reaching quality and used the Grey-TOPSIS-DEA method to evaluate the college aerobics teaching quality. The structure of this paper is as follows. The first part is the introduction. The second part is the basic knowledge. In this part, we introduced the steps of the TOPSIS method and the DEA method. The third part is the improved TOPSIS method: Grey-TOPSIS-DEA. In this part, we proposed the improved TOPSIS method-Grey-TOPSIS-DEA. The fourth part is the numerical experiments We used Grey-TOPSIS-DEA to evaluate the aerobics teaching quality. The last part/is the conclusion.

\section{The Basic Step of DEA Method}

In DEA method, according to the ratio of the weighted sum of the multi output indexes and multi input index in the decision unit, we define the decision unit effectively. We assume that there are $n$ decision units.

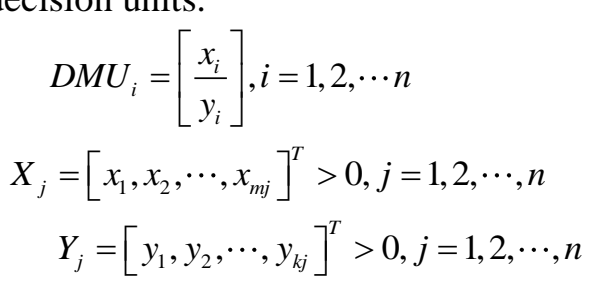

Among them, $D M U_{\text {inespres }}$ exprestput items $x_{1 i}, x_{2 i}, \cdots, x_{m i}$ and $n$ input items

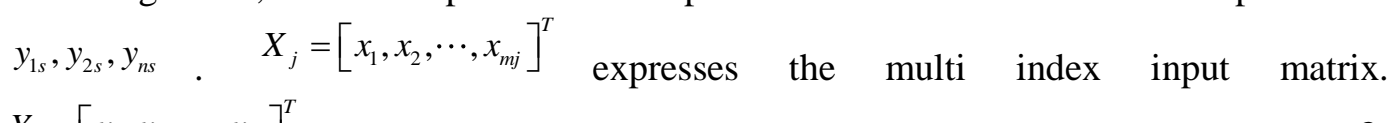
$Y_{j}=\left[y_{1}, y_{2}, \cdots, y_{k j}\right.$ expresses the multi index output matrix. The total output value $Q_{i}$ and the total input value $Y$ of $D M U_{i}$ are as follows.

$$
\text { 20. } \begin{aligned}
Q_{i}=u_{1} y_{1 t}+u_{2} y_{2 t}+\cdots+u_{s} y_{t} & =y_{t}^{T} u \\
I_{i}=v_{1} y_{1 t}+v_{2} y_{2 t}+\cdots+v_{m} y_{m t} & =X_{t}^{T} u
\end{aligned}
$$

The greater the total input value, the smaller the total output value, the higher the computationalefficiency of $D M U^{i}$.According to the ratio between the total output value and the tolal input value of the decision unit, we can measure $D M U_{i}$.

$$
E_{n}=\frac{Q_{i}}{I_{i}}
$$

Among them, $E_{n}$ is the evaluation index of $D M U_{i}$. The weighted vector $u$ and $v$ are not sure. Each component of $u$ and $v$ is greater than zero. For all $D M U_{i}$, according to $C^{2} R$ model and solving the maximize linear programming model, we can obtain the maximize weighted vector that makes each $E_{n}$ of $D M U_{i}$ reach to the maximize value. 


$$
\begin{aligned}
& \max \frac{y_{t}^{T} u}{x_{t} v}=E_{n} \\
& \text { s.y. }\left\{\begin{array}{l}
\frac{y_{j}^{T} u}{x_{j} v} \leq 1(1 \leq j \leq n) \\
u \geq 0 \\
v \geq 0
\end{array}\right.
\end{aligned}
$$

Through Charnes-Coopre transform, we transfer the above type to the equivalent linear model. And we get the following linear programming model.

$$
\begin{aligned}
& \max y_{k}^{T}=E_{n} \\
& \text { s.y. }\left\{\begin{array}{l}
y_{j}^{T} u \leq x_{j}^{T} v(1 \leq j \leq n) \\
x_{j}^{T} v=1 \\
u \geq 0, v \geq 0
\end{array}\right.
\end{aligned}
$$

If the model gets the optimal solutions $u_{t}$ and, the best weight of $D M U_{i}$ is $W_{t}^{T}=\left[\begin{array}{l}V_{t}^{T} \\ U_{t}^{T}\end{array}\right]$. And the output efficiency value of $D M U_{i}$ is $E_{n}=y_{t}^{T} u_{t}^{T}$.

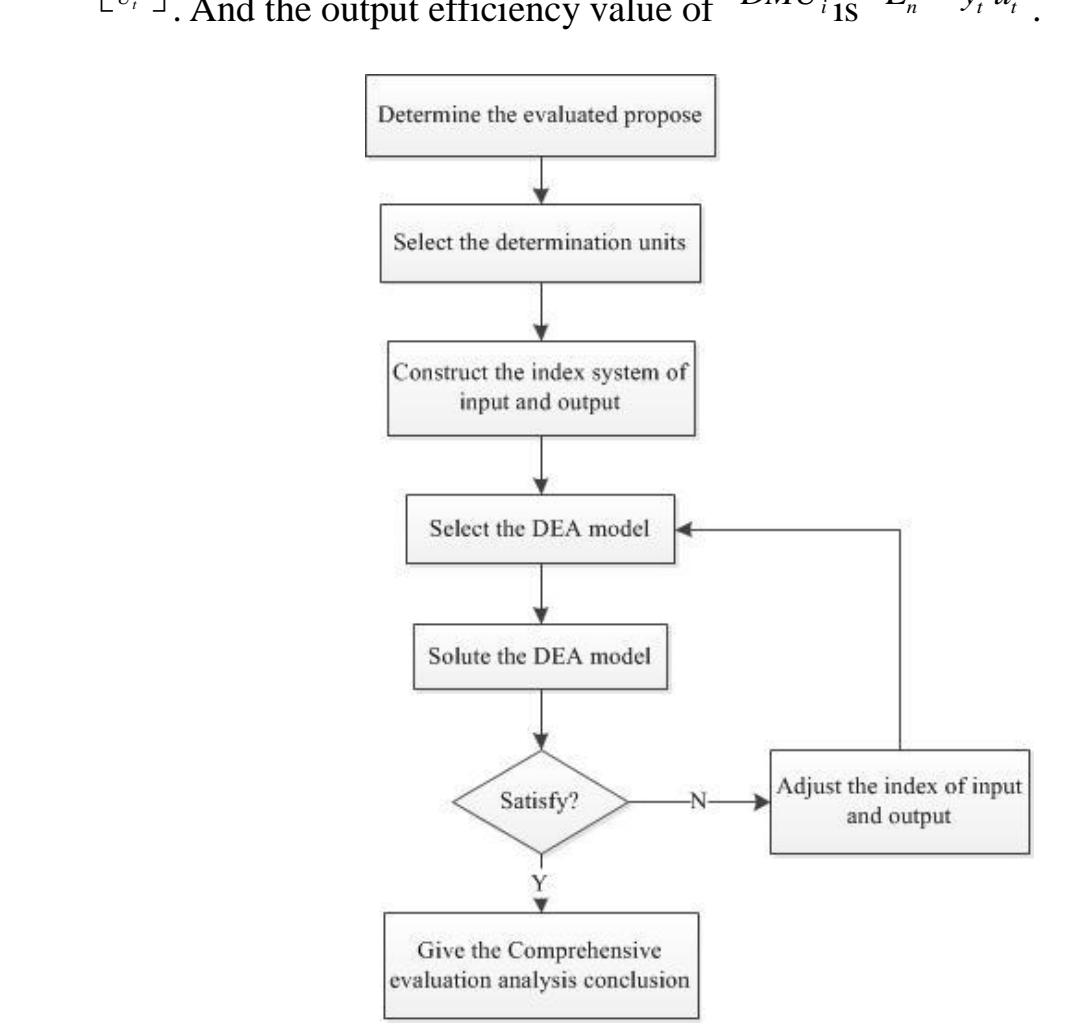

Figure 1. The Flow Chart of DEA

\section{The Improved TOPSIS Method-Grey-TOPSIS-DEA}

In this paper, we put forward an improved TOPSIS method. It is Grey-TOPSIS-DEA method. Firstly, we combine the Grey method with the TOPSIS method. Then we adjust the type according to the results of the output model and the input model by using the DEA method. At last, we use Grey-TOPSIS method to adjust reasonably the ranking.

We assume $A=\left\{A_{1}, A_{2}, \cdots, A_{m}\right\}$ is the scheme set of the multi attribute question. 
$F=\left\{f_{1}, f_{2}, \cdots, f_{n}\right\}_{\text {is }}$ the attribute set of the multi decision question. $X=\left(x_{i j}\right)_{m \times n}$ is the decision matrix. In this decision matrix, $x_{i j}$ is the attribute value for the $j$ attribute in the $i$ scheme. $\omega=\left(\omega_{1}, \omega_{2}, \cdots, \omega\right)^{T}$ is the weighted vector of the attribute which satisfies $\sum_{j=1}^{n} \omega_{j}=1 \quad i=1,2, \cdots, m$ and $j=1,2, \cdots, n$.

The specific steps are as follows.

The first step is to process standardly the original decision matrix $X=\left(x_{i j}\right)_{m \times n}$. And we get $Y=\left(y_{i j}\right)_{m \times n}$.

When the matrix is the benefit decision matrix, we get

$$
y_{i j}=\frac{x_{i j}-\min _{i} x_{i j}}{\max _{i} x_{i j}-\min _{i} x_{i j}}
$$

When the matrix is the cost decision matrix, we get

$$
y_{i j}=\frac{\max _{i} x_{i j}-x_{i j}}{\max _{i} x_{i j}-\min _{i} x_{i j}}
$$

Among them, $i=1,2, \cdots, m, j=1,2, \cdots, n$.

The second step is to determine the positive, ideal solution $Z^{+}$and the negative ideal solution $Z^{-}$.

Among them,

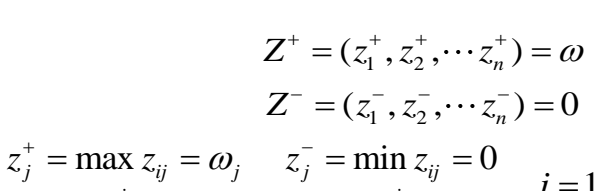

The fourth step isoto calculate the Euclid distance $d_{i}^{+}$and $d_{i}^{-} . d_{i}^{+}$is the distance from each scheme to the posirive ideaksolution. And $d_{i}^{-}$is the distance from each scheme to the negative ideal solution.

$$
\begin{gathered}
d_{i}^{+}=\left\|\mathrm{z}_{i}-A^{+}\right\|=\sqrt{\sum_{j=1}^{n}\left(z_{i j}-z_{j}^{+}\right)^{2}} \\
d_{i}^{-}=\left\|\mathrm{z}_{i}-A^{-}\right\|=\sqrt{\sum_{j=1}^{n}\left(z_{i j}-z_{j}^{-}\right)^{2}} \\
i=1,2, \cdots, m, \quad j=1,2, \cdots, n .
\end{gathered}
$$

The firfth step is to calculate the Gray correlation coefficient matrix $R^{+}$and $R^{-} . R^{+}$is the Grey correlation coefficient matrix from each scheme to the positive ideal solution. $R^{-}$is the Grey correlation coefficient matrix from each scheme to the negative ideal solution.

Among them,

$$
\begin{aligned}
& R^{+}=\left(r_{i j}^{+}\right)_{m \times n} \\
& R^{-}=\left(r_{i j}^{-}\right)_{m \times n}
\end{aligned}
$$

$$
\begin{aligned}
& r_{i j}=\frac{\min _{i} \min _{j}\left|z_{j}^{+}-z_{i j}\right|+\varepsilon \max _{i} \max _{j}\left|z_{j}^{+}-z_{i j}\right|}{\left|z_{j}^{+}-z_{i j}\right|+\varepsilon \max _{i} \max _{j}\left|z_{j}^{+}-z_{i j}\right|}=\frac{\varepsilon \omega_{j}}{\omega_{j}-z_{i j}+\varepsilon \omega_{j}} \\
& r_{i j}=\frac{\min _{i} \min _{j}\left|z_{j}^{-}-z_{i j}\right|+\varepsilon \max _{i} \max _{j}\left|z_{j}^{-}-z_{i j}\right|}{\left|z_{j}^{-}-z_{i j}\right|+\varepsilon \max _{i} \max _{j}\left|z_{j}^{-}-z_{i j}\right|}=\frac{\varepsilon \omega_{j}}{z_{i j}+\varepsilon \omega_{j}}
\end{aligned}
$$


$\varepsilon \in(0,1)$ is the resolution coefficient. In general, we take 0.5 .

The sixth step is to calculate the Grey correlation degree $r^{+}$and $r^{-} \cdot r^{+}$is the Grey correlation degree from each scheme to the positive ideal solution. $r^{-}$is the Grey correlation degree from each scheme to the negative ideal solution.

$$
\begin{aligned}
& r_{i}^{+}=\frac{1}{n} \sum_{j=1}^{n} r_{i j}^{+} \\
& r_{i}^{-}=\frac{1}{n} \sum_{j=1}^{n} r_{i j}^{-}
\end{aligned}
$$

The seventh step is to handle dimensionlessly the distance $d_{i}^{+}$and $d_{i}^{-}$. And we also need to handle dimensionlessly the correlation degree $r^{+}$and $r^{-}$.

$$
\begin{aligned}
& D_{i}^{+}=\frac{d_{i}^{+}}{\max _{i} d_{i}^{+}}, D_{i}^{-}=\frac{d_{i}^{-}}{\max _{i} d_{i}^{-}} \\
& R^{+}=\frac{r_{i}^{+}}{\max _{i} r_{i}^{+}}, R^{-}=\frac{r_{i}^{-}}{\max _{i} r_{i}^{-}} \\
& i=1,2, \cdots,
\end{aligned}
$$

The eighth step is to calculate the relative closehess degree $T_{i}^{+}=\frac{D_{i}^{-}}{D_{i}^{+}+D_{i}^{-}}$and $S_{i}^{+}=\frac{R_{i}^{+}}{R_{i}^{+}+R_{i}^{-}}$. The bigger the value and $S^{+}$are, the more close to the positive ideal solution the scheme is.

The ninth step is to merge $T_{i}$ and $S_{i}^{+}$. Then we determine the weight $v_{1}$ and $v_{2}$.

$$
C_{i}^{+}=v_{1} I_{i}^{+}+v_{2} S_{i}^{+}
$$

Among them, ${ }^{n}$ and $r_{2}$ reflect the preference degree on the position and the shape for the decision makers. $v_{1}+v_{2}=v_{\text {and we take }} v_{1}=v_{2}=\frac{1}{2}$.

The tenth step is to order the schemes according to the size of $C_{i}^{+}$.

After that, we adoptthe DEA model structure to construct the adjusted formula in order to adjust the TOPSIS result. We combine the input and output efficiency with the comprehensive index of the aerobics teaching to evaluate. It not only reflects the comprehensive index value, but also considers the input and output efficiency of the aerobics teaching.

Firstiy, according to calculating each evaluated index value and using the entropy method, we can get the weight $w$ of each index value. Then we adopt the TOPSIS method to get the comprehensive index value $C_{i}$.

Secondly, according to the oriented output DEA model, we get the output efficiency of the fund. And we remember it as $\rho_{\text {out }}$. According to the oriented output DEA model, we get the input efficiency of the fund. And we remember it as $\rho_{\text {in }}$.

Lastly, according to solving the $\rho_{\text {out }}$ and $\rho_{\text {in }}$, we construct the performance adjustment formula and adjust reasonably the comprehensive index value $C_{i}$. Then we get the finial evaluation result.

In order to construct the reasonable adjusted performance value, firstly, we need to explicit the relationship between $\rho_{\text {out }}$ and $\rho_{\text {in }}$. We assume the comprehensive index value of one decision unit is $c$. If we adjust the formula, it needs to satisfy the following conditions. 
Firstly, the adjusted performance value is greater than zero. That is, the adjustment amount is less than ${ }^{c}$.

Secondly, if $\rho_{\text {in }}$ is far away from 1 and near to zero, the adjustment degree is greater. if $\rho_{\text {in }}$ is near to 1 , the adjustment degree is smaller.

Thirdly, if $\rho_{\text {out }}$ is near to 1 , the adjustment degree is smaller. if $\rho_{\text {out }}$ is far away from 1 , the adjustment degree is greater.

Fourthly, when $\rho_{\text {in }}=\rho_{\text {out }}=1$, it needs not to adjust the performance value.

In order to meet the above requirements, this paper constructs the performance adjustment formula.

$$
\Delta c=c \cdot \sqrt{\frac{\left(1-\rho_{\text {in }}\right)\left(1-\frac{1}{\rho_{\text {out }}}\right)}{4}}
$$

The adjusted decision unit index value is as follows.

$$
c_{\text {new }}=c-\Delta c
$$

\section{Numerical Experiments}

We evaluate the teaching quality of the aerobics for five unversities. We use $a, b, c, d$ and e to express the five universities. We evaluate it from eight aspects. The eight aspects are class performance, teaching method, teaching content, gymnastics, comprehensive ability, physical quality, learning effect and learning interest. The weights are as follows.

Table 1. The Indexes and the Weights

\begin{tabular}{|c|c|c|}
\hline Index & Category & Weight \\
\hline \multirow{3}{*}{ Class teåching } & class performance & 0.09 \\
\cline { 2 - 3 } & teaching method & 0.17 \\
\cline { 2 - 3 } & teaching content & 0.10 \\
\hline \multirow{2}{*}{ Teaching effect } & gymnastics & 0.11 \\
\cline { 2 - 3 } & comprehensive ability & 0.25 \\
\cline { 2 - 3 } & physical quality & 0.12 \\
\hline Learning aquitude & learning effect & 0.08 \\
\cline { 2 - 3 } & learning interest & 0.08 \\
\hline
\end{tabular}

The aerobics teaching quality evaluation table of the five universities are as follows.

Table 2. The Scores of the Five Universities

\begin{tabular}{|c|c|c|c|c|c|c|c|c|}
\hline $\begin{array}{c}\text { Univer } \\
\text { sity }\end{array}$ & $\begin{array}{c}\text { Class } \\
\text { perform } \\
\text { ance }\end{array}$ & $\begin{array}{c}\text { Teachin } \\
\mathrm{g} \\
\text { method }\end{array}$ & $\begin{array}{c}\text { Teachin } \\
\mathrm{g} \\
\text { content }\end{array}$ & $\begin{array}{c}\text { Gymn } \\
\text { astics }\end{array}$ & $\begin{array}{c}\text { Compre } \\
\text { hensive } \\
\text { ability }\end{array}$ & $\begin{array}{c}\text { Physic } \\
\text { al } \\
\text { quality }\end{array}$ & $\begin{array}{c}\text { Learni } \\
\text { ng } \\
\text { effect }\end{array}$ & $\begin{array}{c}\text { Learni } \\
\text { ng } \\
\text { interes } \\
\text { t }\end{array}$ \\
\hline A & 8 & 9 & 6 & 9 & 8 & 7 & 9 & 7 \\
\hline B & 7 & 8 & 8 & 6 & 8 & 8 & 6 & 7 \\
\hline C & 6 & 7 & 9 & 7 & 7 & 8 & 7 & 8 \\
\hline D & 9 & 7 & 6 & 7 & 9 & 7 & 8 & 8 \\
\hline E & 8 & 9 & 8 & 8 & 8 & 9 & 9 & 7 \\
\hline
\end{tabular}

Firstly, we normalize the matrix and get the weighting matrix. 


$$
z=\left[\begin{array}{cccccccc}
0.131 & 0.173 & 0.108 & 0.173 & 0.150 & 0.115 & 0.151 & 0.115 \\
0.089 & 0.098 & 0.121 & 0 & 0.150 & 0.134 & 0 & 0.115 \\
0 & 0 & 0.127 & 0.104 & 0.133 & 0.134 & 0.113 & 0.123 \\
0.173 & 0 & 0.108 & 0.104 & 0.200 & 0.115 & 0.121 & 0.123 \\
0.131 & 0.173 & 0.121 & 0.120 & 0.150 & 0.151 & 0.151 & 0.115
\end{array}\right]
$$

Secondly, we determine the positive ideal solution and the negative ideal solution for the weighted normalized matrix.

$$
\begin{gathered}
Z^{+}=[0.13,0.17,0.20,0.20,0.15] \\
Z^{-}=[0,0,0,0,0]
\end{gathered}
$$

Thirdly, we compute the Euclid distance among each scheme and the positive ideal solution. Then, we compute the Euclid distance among each scheme and the negative ideal solution.

$$
\begin{aligned}
& d^{+}=(0.336,0.178,0.065,0.333,0.324) \\
& d^{-}=(0.213,0.326,0.388,0.121,0.289)
\end{aligned}
$$

We calculate the Grey correlation degree between each seheme and the positive ideal solution. We also need to calculate the Grey correlation degree between each scheme and the negative ideal solution.

$$
\begin{gathered}
r^{+}=(0.786,0.896,0.944,0.637,0.866) \\
r^{-}=(0.853(0.768,0682,8.924,0.752)
\end{gathered}
$$

Then we calculate the relative closeness degree.

$$
\begin{aligned}
& T^{+}=(0.274,0.266 .0210,0.135,0.281) \\
& S^{+} €(0.219,0278,0.278,0.146,0.259)
\end{aligned}
$$

Finally, we count the $C_{i}$ with $y_{1}=v_{2}=\frac{1}{2}$

$$
C_{i}=(0.416,0.572,0.684,0.408,0.569)
$$

Then, we continue to adopt the TOPSIS method to calculate each index. We take the eight indexes as the inputelements of the DEA model input unit. The output unit is the fund performance-comprehensive value. We take $z_{i j}$ and $c_{j}$ as the input unit and output unit of DEA model. Then we apply EMS software to solve the input and output DEA results. Next we use the performance adjustment formula to get the adjustment amount $\Delta$. According to $c-\Delta c$, we calculate the finial adjusted performance value and rank the comprehensive performance value. The adjusted results are as follows.

Table 3. The Rank after Adjusting for DEA

\begin{tabular}{|c|c|c|c|c|c|c|}
\hline university & $\rho_{\text {in }}$ & $\rho_{\text {out }}$ & $C_{i}$ & adjusted $C_{i}$ & $\begin{array}{c}\text { Rank before } \\
\text { adjusting }\end{array}$ & $\begin{array}{c}\text { Rank after } \\
\text { adjusting }\end{array}$ \\
\hline $\mathrm{A}$ & 1 & 1 & 0.416 & 0.416 & 4 & 4 \\
\hline $\mathrm{B}$ & 0.77 & 1.3 & 0.572 & 0.529 & 2 & 3 \\
\hline $\mathrm{C}$ & 0.97 & 1.3 & 0.684 & 0.679 & 1 & 1 \\
\hline $\mathrm{D}$ & 0.99 & 1.01 & 0.408 & 0.407 & 5 & 5 \\
\hline $\mathrm{E}$ & 0.83 & 1.2 & 0.569 & 0.537 & 3 & 2 \\
\hline
\end{tabular}

From the above table, the adjusted result can consider the input and output efficiency of aerobics teaching. The adjusted evaluation result is more reasonable. Therefore, the evaluation method that this paper constructs can achieve better study purpose. 


\section{Conclusion}

Aerobics is a sport that is received by teachers and students. It is a universal sport. Aerobics sport is an aerobic exercise which combines fitness with entertainment. In China, we host an annual Bodybuilding Championships. And each university almost carries out the aerobics competition every year. According to assessing the aerobics sport, it can strengthen the aerobics management, ensure the aerobics teaching quality and promote the further development of the aerobics in colleges. This paper has done the following work. Firstly, we introduce China's aerobics status and the background. Secondly, we introduce the basic steps of the TOPSIS method and DEA method. Thirdly, aiming to the evaluation requirement of colleges' aerobics, we put forward Grey-TOPSIS-DEA method. Finally, we apply the Grey-TOPSIS-DEA method to the college sport teaching evaluation. And we establish the college sport teaching evaluation system and evaluate the aerobics teaching for each university.

\section{References}

[1] Z. Xiaoying, W. Lihong, M. Hongtao and W. Dehua, "Practical Research on Caltivating Students' Creativity Ability in the Teaching of Special Curriettum of Aerobics", Journal of Beijing Sport University, vol. 29, no. 1, (2006), pp. 104-106.

[2] L. Yunlin and C. Min, "Research on Artistic Value of New Code Aerobjes Composition", Journal of Sports and Science, vol. 11, (2009), pp. 53-56.

[3] Y. Liqin, "The Evolution of International Competivive Calisthenieg Rules", Journal of Beijing Sport University, vol. 33, no. 8, (2010), pp. 128-13,

[4] L. Ling, "The Research about Aerobics(Dynamic Analyss in China during 1992-2011", Shanghai University Of Sport, Physical Education Training, (2013).

[5] Y. Xiao, "The research of the Aerbbios Professional Teaching ability of the graduations of Henan University", Henan University (Physical Education Training, (2013).

[6] Y. Guang, "The Researched on the Group Cooperative Learning Method in College Aerobics Teaching", Northeast Normal University Physical Education. (2013).

[7] M. Behzadian, S. K. Otaghsara, M. Yazany and J. Ignatius, "A state-of the-art survey of TOPSIS applications”, Expert Systens with Applications, vol. 39, no. 17, (2012), pp. 13051-13069.

[8] X. Zhongyou, "Study on the Application of TOPSIS Method to the Introduction of Foreign Players in CBA Games", Physics Proceeding, vol. 33, no. 33, (2012), pp. 2034-2039.

[9] C. Tan, "A multi criteria interval-valued intuitionistic fuzzy group decision making with Choquet integral-based TOPSIS”, Expert Systems with Applications, vol. 38, no. 4, (2011), pp. 3023-3033.

[10] C. C. Sun, "A performance evaluation model by integrating fuzzy AHP and fuzzy TOPSIS methods", Expert Systems with Applications, vol. 37, no. 12, (2010), pp. 7745-7754.

[11] J. H. Huang and K. H. Peng, "Fuzzy Rasch model in TOPSIS: A new approach for generating fuzzy numbers to asøess the competitiveness of the tourism industries in Asian countries", Tourism Management, vol. 33, no. 2, (2012), pp. 456-465.

[12] K. Mandic, B. Delibasic, S. Knezevic and S. Benkovic, "Analysis of the financial parameters of Serbian banks through the application of the fuzzy AHP and TOPSIS methods", Economic Modelling, vol. 43, (2014), pp. 40-47.

[13] T. Y. Chen, "The inclusion-based TOPSIS method with interval-valued intuitionistic fuzzy sets for multiple criteria group decision making", Applied Soft Computing, vol. 26, (2015), pp. 57-73.

[14] E. Keshavarz and M. Toloo, "Finding efficient assignments: An innovative DEA approach", Measurement, vol. 58, (2014), pp. 448-458.

[15] T. Sueyoshi and M. Goto, "A combined use of DEA (Data Envelopment Analysis) with Strong Complementary Slackness Condition and DEA-DA (Discriminant Analysis)", Applied Mathematics Letters, vol. 24, no. 7, (2011), pp. 1051-1056.

[16] P. J. Korhonen, M. Damaneh and J. Wallenius, "Ratio-based RTS determination in weight-restricted DEA models", European Journal of Operational Research, vol. 215, no. 2, (2011), pp. 431-438.

[17] W. D. Cook, L. Liang and J. Zhu, "Measuring performance of two-stage network structures by DEA: A review and future perspective", Omega, vol. 38, no. 6, (2010), pp. 423-430.

[18] Y. Li, F. Yang, L. Liang and Z. Hua, "Allocating the fixed cost as a complement of other cost inputs: A DEA approach", European Journal of Operational Research, vol. 197, no. 1, (2009), pp. 389-401.

[19] M. Lijie, "Research on theory and application of DEA", Shandong University, operational research and cybernetics, (2007).

[20] W. Quanhua, "Further study of the DEA method", Tianjin University, management science and engineering, (2008).

[21] B. Yiwen, "Study on environmental efficiency evaluation method based on DEA theory", University of 
International Journal of Multimedia and Ubiquitous Engineering

Vol.11, No.8 (2016)

Science and Technology of China, management science and engineering, (2006).

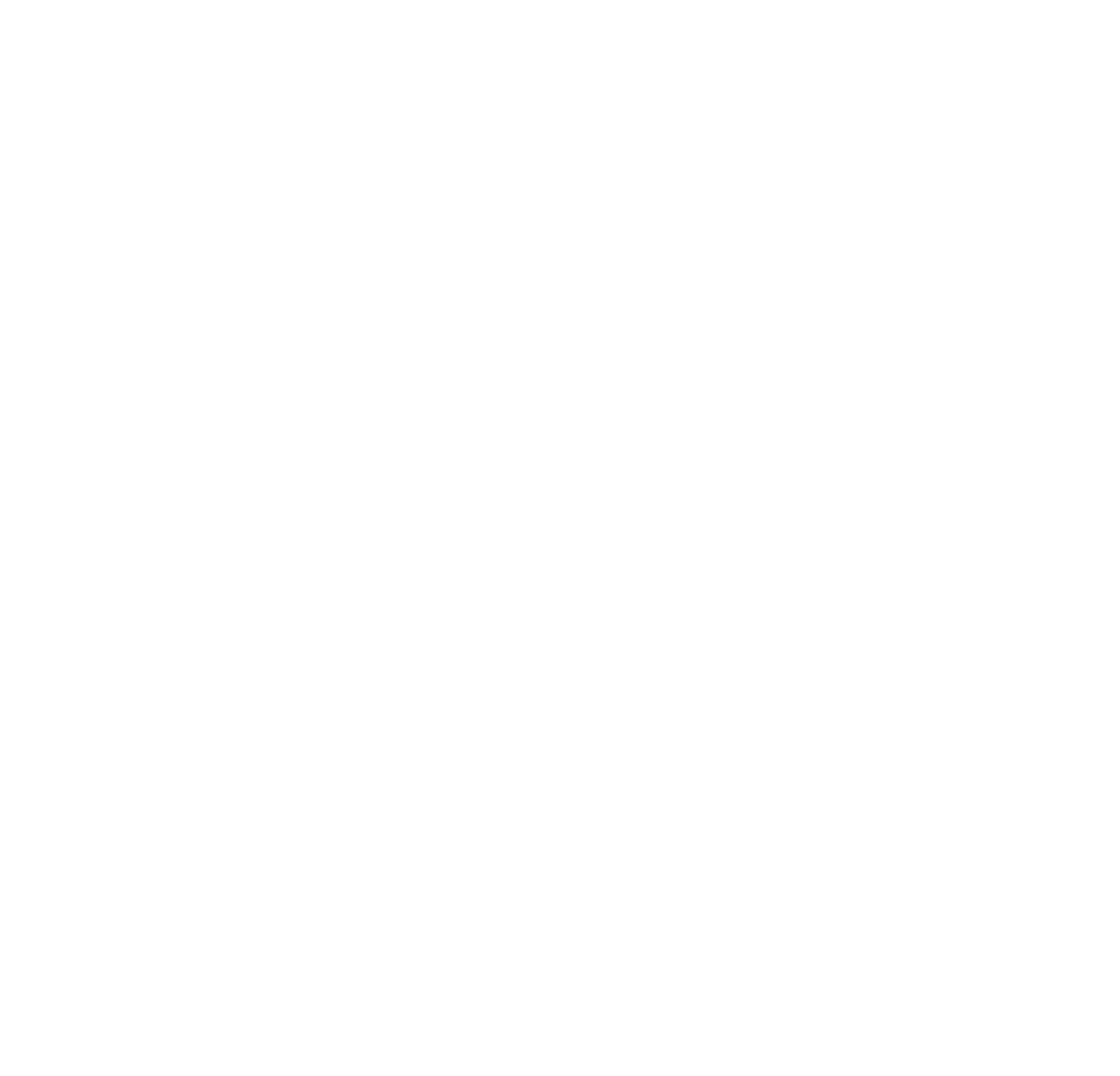

